\title{
The significance of relatedness in healthcare
}

\author{
Henk ten Have $\cdot$ Bert Gordijn
}

Published online: 13 February 2014

(C) Springer Science+Business Media Dordrecht 2014

The tradition of anthropological medicine in the first half of the twentieth century regarded medicine first of all as a relational activity. Its aim was to develop medicine as a science of human beings, building on the ideas of phenomenology, existentialism and philosophical anthropology (Ten Have 1995). Rather than applying the findings of scientific disciplines such as biology, genetics, chemistry or physics to human beings, following strict methodological rules or operating as a practical art, anthropological medicine emphasized the personal qualities of the healthcare professional and acknowledged the subjectivity of patients and doctor, medicine being in between science and art. How to create a genuinely humane medicine and physiology was the major challenge for Buytendijk (Dekkers 1995). Crucial notions in his work are 'relation' and 'relatedness.' Medicine essentially is a relational activity. It is basically characterized by what we nowadays would call connectivity. Another basic notion for Buytendijk was 'encounter.' Like his German colleagues Von Weizsäcker and Von Gebsattel he wrote extensively about the doctor-patient relationship, which he did not simply regard as the interaction of health provider and health consumer. Rather it was the expression of the more fundamental situatedness of human beings in general. Our bodily existence is always situated in our 'life-world.' Existence means connecting to others, exceeding one's individual boundaries. The notion of relationship therefore has a more fundamental significance. It is constitutive for human existence since it would not be possible without relatedness to other beings. But it is also the primordial phenomenon for the theory and practice of medicine, since the plea for help of someone in need constitutes the enterprise

H. ten Have $(\varangle) \cdot$ B. Gordijn

Pittsburgh, PA, USA

e-mail: tenhaveh@duq.edu of medicine, establishing a relationship between the ill and needy and professionals who respond with help and care (Von Weizsäcker 1951; Welie 1995). Thus medicine's point of departure is - in a manner of speaking — "relational ontology" (Martinsen 2013, p. 65).

The significance of relatedness is exemplified in the anthropology that characterizes this philosophical tradition. It assumes, what Dekkers calls the "indissoluble relationship" between person, body, consciousness and world (Dekkers 1995, p. 20). Human beings cannot be separated into a physical and mental component, into body and self. In addition, the dualism in the scientific epistemology between object and subject must be challenged. We generally assume that there is an objective real world independent of an isolated individual subject. The anthropology of relatedness rejects such a distinction because it prevents that scientific methodology can grasp what is typical for human beings. If they are dissected, disintegrated and disconnected through abstract analytic approaches, they cannot be comprehended and approached as persons. The coherence and interrelationships that are defining living beings are lost. In this way, medicine cannot fully understand disease and illness. According to Von Weizsäcker (1951) being ill is a way of being a human person, an existential mode. Having a disease and being ill are two sides of the same coin. Similarly, human beings do not only have a body but at the same they are their body. In other words, organic life $(\zeta \omega \eta)$ and biographical life $(\beta \uparrow \varsigma \varsigma)$ are intrinsically related. This connectedness explains the emphasis on passivity in the anthropological tradition. Human beings are not only characterized by activity and control, but they are also subjected to experiences and possibilities. Everyday life has, in the words of Von Weizsäcker, a 'pathic' nature that cannot be eliminated by interventions. 
These early perspectives of anthropological medicine continue to be reiterated in modern philosophy of medicine. In their seminal work, for example, Pellegrino and Thomasma portrayed medicine as "a specific kind of relationship" somewhere between art and science (Pellegrino and Thomasma 1981, p. 65). A very similar emphasis on relatedness is articulated in contemporary studies. Gaille (2011), for example, explains that medicine has a double face: it is a form of and a search for knowledge, but at the same time it involves a caring relation and social practice. Aurenque and Friedrich (2014) argue that the relational nature of medicine is the continuous source of ethical problems.

The crucial role of the notion of relatedness is demonstrated in several contributions in the current issue of the journal, specifically in the context of donation, addiction and child obesity. Zeiler (2014) argues that the discourse of organ donation can be enriched through rethinking the relation between self and other. Taking seriously the dimension of relatedness will deemphasize the individual and its boundaries (regarding bodies and organs as property of the individual). But one should also be careful not to regard relatedness as reciprocity, so that donation is regarded as a heroic act or sacrifice that invites an exchange in return. Zeiler argues hat relationality goes beyond the individual and the framework of economic exchange: the connectedness of self and other implies a framework of sharing. It is based on the view that giving and being-given characterize human existence. Since the self is determined and constituted in relations with others, human beings are basically open to others; human existence can only be co-existence. In this perspective, relatedness means sharing, and donating should be the normal human situation. This reasoning is inspired and motivated by Continental philosophy, and specifically phenomenology. It also elaborates and applies basic ideas of the earlier anthropological tradition in medicine.

Similar motivations and inspirations can be found in the article of Reyre et al. (2014). They emphasize the significance of relatedness in addiction care. Arguing that stigmatization and stereotyping can negatively impact the relationship with addicted patients, building and cultivating trust will be essential components of relating to these patients, enabling adequate care.

Finally, Merry and Voigt (2014) demonstrate that relatedness is an equally important notion in care for children with obesity. Referring to a recent case where three children were placed under state supervision and removed from parental authority because of their weight, they question the exclusive focus on the individual children. What cannot be ignored in the case is the relatedness, first between the children and their parents, and second between obesity and an 'obesogenic environment.' Rather than regarding obesity as individual failure or misguided choice, one should assume that children in general flourish much better in a family setting with concerned and loving parents than under state regulated supervision. But the essential connectedness of individuals furthermore implies that individual existence is continuously impacted by the social context. This relatedness may produce vulnerability, disadvantages and stigmatization beyond the control of individuals. Contrary to the often-repeated message of individual autonomy, the human self is not detached and alone.

\section{References}

Aurenque, D. and O. Friedrich (eds). 2014. Medizinphilosophie oder philosophische Medizin/Philosophisch-ethische Beiträge zu Herausforderungen technisierter Medizin. Stuttgart-Bad Cannstatt: fromman-holzboog.

Dekkers, W.J.M. 1995. FJJ Buytendijk's concept of an anthropological physiology. Theoretical Medicine 16(1): 15-39.

Gaille, M. (ed.). 2011. Philosophie de la médecine: Frontière, savoir, clinique. Paris: Librairie Philosophique J. Vrin.

Martinsen, E.H. 2013. Towards a medical ethics that cares: A theoretical and normative study of ill-being and care in medicine. Oslo: Akademika Publishing, University of Oslo.

Merry, M.S. and K. Voigt. 2014. Risk, harm and intervention: the case of child obesity. Medicine Health Care and Philosophy 17(2): this issue.

Pellegrino, E.D., and D.C. Thomasma. 1981. A philosophical basis of medical practice: Toward a philosophy and ethics of the healing professions. New York, Oxford: Oxford University Press.

Reyre, A., R. Jeannin, M. Larguèche, E. Hirsch, T. Baubet, M.R. Moro, and O. Taïeb. 2014. Care and prejudice: moving beyond mistrust in the care relationship with addicted patients. Medicine Health Care and Philosophy 17(2): this issue.

Ten Have, H. 1995. The anthropological tradition in the philosophy of medicine. Theoretical Medicine 16(1): 3-14.

Von Weizsäcker, V. 1951. Der kranke Mensch: Eine Einführung in die Medizinische Anthropologie. Stuttgart: K.F. Köhler.

Welie, J.V.M. 1995. Viktor Emil von Gebsattel on the doctor-patient relationship. Theoretical Medicine 16(1): 41-72.

Zeiler, K. 2014. Neither property rights nor heroic gift, neither sacrifice nor aporia: The benefit of the theoretical lens of sharing in donation ethics. Medicine Health Care and Philosophy 17(2): this issue. 